\title{
Association between isolated hypothyroxinaemia in early pregnancy and perinatal outcomes
}

\author{
Xiujuan Su${ }^{1}$, Yan Zhao', Zhijuan Cao ${ }^{1}$, Yingying Yang ${ }^{1}$, Tony Duan ${ }^{2}$ and Jing Hua ${ }^{1}$ \\ ${ }^{1}$ Department of Women \& Children's Health Care, Shanghai First Maternity and Infant Hospital, Tongji University School of Medicine, Shanghai, China \\ 2Department of Obstetrics, Shanghai First Maternity and Infant Hospital, Tongji University School of Medicine, Shanghai, China \\ Correspondence should be addressed to J Hua: huajing_mih@163.com
}

\begin{abstract}
Background: The effect of isolated maternal hypothyroxinaemia (IMH) on pregnancy complications and neonatal outcomes in human beings is still controversial.

Methods: This was a retrospective cohort study based on the electronic medical register system. The records of women with a singleton pregnancy who sought antenatal examination between January 2014 and December 2015 at Shanghai First Maternity and Infant Hospital were extracted from the electronic medical records system. Thyroidstimulating hormone (TSH), free thyroxine ( $\mathrm{fT} 4$ ) and anti-thyroperoxidase autoantibody (TPO-Ab) was measured before 20 gestational weeks, and a multiple logistic regression model was used to estimate the odds ratios of pregnancy complications and neonatal outcomes between euthyroid women and those with isolated hypothyroxinaemia. Results: A total of 8173 women were included in this study, of whom 342 (4.18\%) were diagnosed with $\mathrm{IMH}$. Regression analysis showed that IMH diagnosed in the second trimester (13-20 weeks) was associated with an increased risk of hypertensive disorders of pregnancy $(\mathrm{OR}=2.66,95 \% \mathrm{Cl}: 1.38-5.10)$ and placenta abruption $(\mathrm{OR}=3.64,95 \% \mathrm{Cl}$ : 1.07-12.41), but not with preterm delivery $(\mathrm{OR}=1.09,95 \% \mathrm{Cl}: 0.50-2.40)$, small or large gestational age of infant $(\mathrm{OR}=0.91,95 \% \mathrm{Cl}: 0.39-2.12 ; \mathrm{OR}=1.16,95 \% \mathrm{Cl}: 0.72-1.86)$, macrosomia $(\mathrm{OR}=1.71,95 \% \mathrm{Cl}: 0.95-3.07)$, gestational diabetes mellitus $(\mathrm{OR}=1.36$, 95\% Cl: $0.86-2.15)$ and placenta previa ( $\mathrm{OR}=1.62,95 \% \mathrm{Cl}: 0.39-7.37)$. Conclusion: IMH could be a risk factor for hypertensive disorders of pregnancy.
\end{abstract}

\section{Key Words}

- thyroid dysfunction

- hypothyroxinaemia

- pregnancy complications

- hypertensive disorders of pregnancy

\section{Introduction}

Pregnancy has a profound impact on the thyroid gland and its function, so it is not surprising that thyroid diseases are relatively frequently observed among pregnant women. Maternal thyroid hormones are known to be crucial for normal foetal growth and development in childhood $(1,2,3)$. This is particularly true in the first trimester when the foetus is entirely dependent on the transplacental passage of maternal thyroid hormones $(4,5)$. The prevalence of thyroid disease varies widely in its subtypes and populations $(6,7)$. A systematic review reported that pooled prevalence of thyroid dysfunction, using the 97.5th percentile as an upper limit for TSH, ranges from 0.5 to $3.5 \%$ in different subtypes (8).

Treatment of overt hyperthyroidism or hypothyroidism during pregnancy has been suggested by the American Thyroid Association (ATA) and the Endocrine Society due to its negative effect on the foetus and mother $(9,10)$. Although there are some controversial results on the effect of subclinical hypothyroidism or hyperthyroidism on health, a randomised controlled trial showed that treatment of subclinical hypothyroidism appears beneficial for women who were undergoing in vitro fertilisation (11).

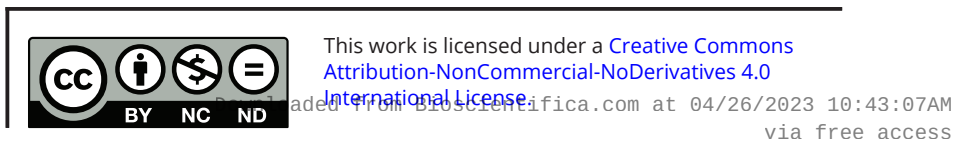


However, the link between isolated hypothyroxinaemia and mother and foetal health is still a matter of debate $(12,13)$.

Based on the electronic medical records system, we performed a study to estimate IMH in early pregnancy ( $\leq 20$ weeks) and the risk of a series of pregnancy complications and neonatal outcomes, including gestational diabetes mellitus, hypertensive disorders of pregnancy, preterm delivery, placenta previa, placenta abruption and neonatal weight-related outcomes.

\section{Subjects and methods}

This was a hospital-based, retrospective cohort study. The records of women with a singleton pregnancy who sought antenatal examination between January 2014 and December 2015 at Shanghai First Maternity and Infant Hospital were extracted from the electronic medical records system $(n=24,762)$. The study was approved by the Ethics Committee of Shanghai First Maternity and Infant Hospital, Tongji University School of Medicine. Consent has been obtained from each patient or subject after full explanation of the purpose and nature of all procedures used. The study was performed in accordance with the approved guidelines.

\section{Population}

The study population is shown in a flow chart (Fig. 1). Women with full information on all thyroid function indexes were included in the study, including for TSH, free thyroxine (fT4) and anti-thyroperoxidase autoantibody (TPO-Ab) $(n=12,159)$. Those women with positive TPO-Ab $(>60 \mathrm{U} / \mathrm{mL})$ were excluded from the study first $(n=1338)$. Women with implausible gestational age
(>44 gestational weeks, $n=284$ ), diagnosis of gestational age for thyroid function earlier than last menstrual period or after 20 gestational weeks $(n=1705)$ or with history of thyroid illness according to their medical history $(n=84)$ were also excluded from the study. According to the study design, except for women with a diagnosis of isolated hypothyroxinaemia, those diagnosed with other thyroid diseases, including overt hyperthyroidism ( $n=96)$, subclinical hyperthyroidism $(n=186)$, hypothyroidism $(n=16)$, subclinical hypothyroidism $(n=212)$ or high fT4 but normal TSH concentration $(n=65)$ were also excluded from the analysis. Finally, a total of 8173 women were included in the final analysis.

\section{Thyroid function tests}

Serum samples from women who presented for prenatal care in the first half of pregnancy were retrieved, and the thyroid function indexes were measured, including $\mathrm{TSH}$, fT4 and TPO-Ab. The reference values for TSH and fT 4 were determined by using the 2.5th and 97.5th percentiles for gestational age in our institution. For the first trimester, the reference intervals were $0.06-3.83 \mathrm{mIU} / \mathrm{L}$ for TSH and $1.01-1.57 \mathrm{ng} / \mathrm{dL}$ for fT4. For the second trimester, they were $0.07-4.08 \mathrm{mIU} / \mathrm{L}$ for TSH and $0.95-1.53 \mathrm{ng} / \mathrm{dL}$ for fT4 (14). The detailed information on thyroid function tests was described in our previously published article (14). Isolated hypothyroxinaemia is defined by a lower fT4 level ( $\leq 2.5$ th percentile) with normal TSH concentration and negative TPO-Ab, according to the Chinese Society of Endocrinology in this study.

\section{Main pregnancy outcomes}

Information on pregnancy outcomes was obtained through medical records. Gestational age was based on

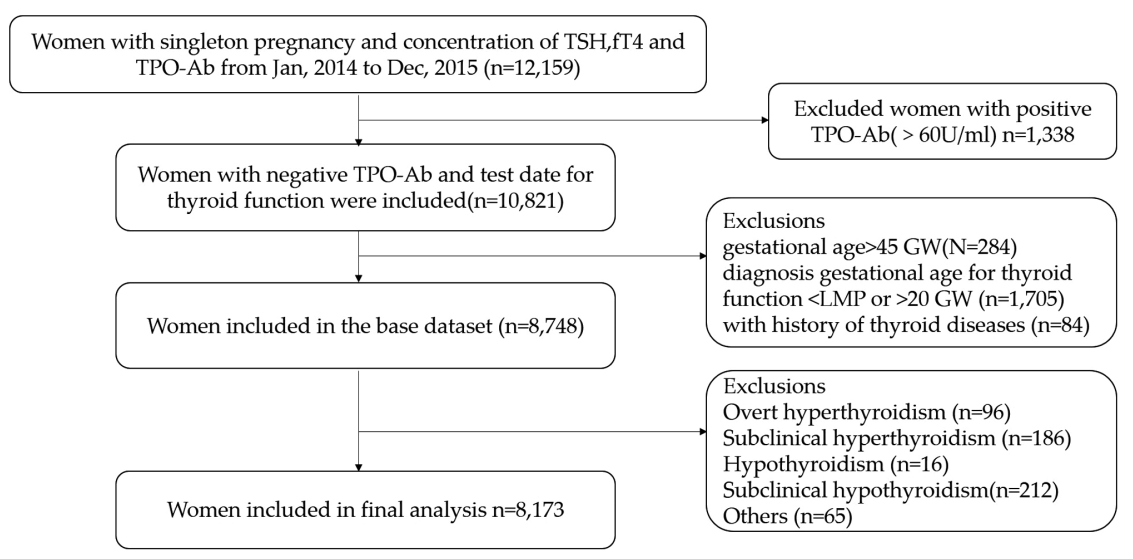

Figure 1

Flow chart concerning the study population. https://ec.bioscientifica.com https://doi.org/10.1530/EC-19-0088 (c) 2019 The authors Published by Bioscientifica Ltd
This work is licensed under a Creative Commons Attribution-NonCommercial-NoDerivatives 4.0 Internationab sicense.ifica . com at 04/26/2023 10:43:07AM 
the interval between last menstrual period and date of delivery of the baby. When the menstrual estimate of gestational age was inconsistent by 7 or more days within the ultrasound measurement, we used the ultrasoundcorrected gestational age. According to the birthweight, the newborn could be classified into three groups: low birth weight (LBW, $<2500 \mathrm{~g})$, macrosomia $(\geq 4000 \mathrm{~g})$ and optimal birthweight. Small for gestational age (SGA) and large for gestational age (LGA) identified newborns whose birthweight was below the 10th percentile and above the 90th percentile, respectively, according to the Chinese birth weight reference percentiles (15). Preterm delivery was defined as births with gestational age less than 37 weeks. A $75 \mathrm{~g}$ oral glucose tolerance test at 24-28 weeks of gestation was performed. Women with a fasting blood glucose level $\geq 5.1 \mathrm{mmol} / \mathrm{L}$, a 1-h blood glucose level $\geq 10.0 \mathrm{mmol} / \mathrm{L}$ or a 2 -h blood glucose level $\geq 8.5 \mathrm{mmol} / \mathrm{L}$ were diagnosed with gestational diabetes mellitus (GDM). Women with systolic blood pressure $\geq 140 \mathrm{mmHg}$ and/or diastolic blood pressure $\geq 90 \mathrm{mmHg}$ in any visit after the 20th week of gestation were considered to have hypertensive disorders of pregnancy. Placenta previa and placenta abruption were also observed in this study.

\section{Statistical analysis}

The basic characteristics of pregnant women were compared using the Student's $t$-test for quantitative variables and the $\chi^{2}$ test for categorical variables between the euthyroid and IMH groups. We used logistic regression models to evaluate the odds ratios (ORs) of women with an IMH diagnosis, compared with euthyroid women. According to the previous studies, we adjusted for the following confounders in multiple-regression models: BMI $(<18.5,18.5-23.9, \geq 24)$, health insurance (yes, no), gravidity $(1,2, \geq 3)$, parity (primipara, multipara), family history of chronic disease (yes, no) and newborn sex (boy, girl). Family history of chronic disease was defined by selfreported information at the initial antenatal visit, and included diabetes mellitus, hypertension, heart diseases and kidney diseases. We also investigated the association between IMH and pregnancy outcomes by trimester. Because birthweight was associated with hyperglycaemia, we adjusted the maternal diabetes status (GDM: yes, no) according to the association between IMH and neonatal outcomes. All data were analysed by using SAS for Windows, version 9.4 (SAS Institute, Inc.). A $P<0.05$ was considered statistically significant.

Table 1 Basic characteristic of the population between euthyroid and $\mathrm{IMH}^{\&}$.

\begin{tabular}{l} 
Basic characteristic \\
\hline Maternal age at pregnancy \\
Gestational age (days) \\
Menarche age (years) \\
BMI \\
$<18.5$ \\
$18.5-23.9$ \\
$\geq 24$ \\
Health insurance \\
Yes \\
No \\
Newborn sex \\
Boy \\
Girl \\
Family history of chronic diseases \\
Yes \\
No \\
Gravidity \\
1 \\
2 \\
$\geq 3$ \\
Parity \\
Primipara \\
Multipara \\
TSH \\
fT4* \\
\hline
\end{tabular}

\begin{tabular}{c}
\hline Euthyroid $(n=7831)$ \\
\hline $29.76 \pm 3.75$ \\
$275.41 \pm 9.41$ \\
$13.81 \pm 1.52$ \\
$1162(24.46)$ \\
$3047(64.13)$ \\
$542(11.41)$ \\
$5803(74.10)$ \\
$2028(25.90)$
\end{tabular}

4052 (51.74)

$3779(48.26)$

2311 (29.51)

$5520(70.94)$

$4410(56.33)$

2039 (26.04)

$1380(17.63)$

6258 (79.91)

1573 (20.09)

$1.39(0.89-2.02)$

$1.17(1.09-1.26)$

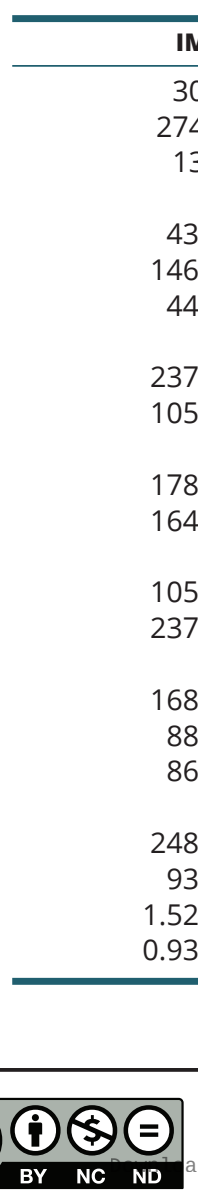

IMH $(n=342)$

$274.47 \pm 10.41$

$13.78+1.45$

$43(18.45)$

$146(62.66)$

$44(18.88)$

$237(69.30)$

$105(30.70)$

0.0477

$178(52.05)$

$164(47.95)$

0.9124

$105(30.70)$

$237(69.30)$

0.6378

$168(49.12)$

$88(25.73)$

$86(25.15)$

0.0012

$248(72.73)$

$93(27.27)$

0.0013

$52(1.06-2.13)$

0.0004

$0.93(0.90-0.94)$

\&isolated maternal hypothyroxinemia; *median (Q25-Q75).

https://ec.bioscientifica.com https://doi.org/10.1530/EC-19-0088 (c) 2019 The authors Published by Bioscientifica Ltd
This work is licensed under a Creative Commons Attribution-NonCommercial-NoDerivatives 4.0 Internationab kicense.ifica com at 04/26/2023 10:43:07AM 
Table 2 Association between IMH and neonatal outcomes.

\begin{tabular}{lcc}
\hline Neonatal outcomes & & Euthyroid $(n=7831)$ \\
\cline { 1 - 1 } LBW $^{a}(<2500 \mathrm{~g})$ & & $210(2.68)$ \\
Macrosomia $(\geq 4000 \mathrm{~g})$ & & $457(5.84)$ \\
Normal birthweight $(2500-4000 \mathrm{~g})$ & $7164(91.48)$ \\
SGA $^{\mathrm{b}}$ & & $344(4.39)$ \\
LGA $^{c}$ & $1028(13.13)$ \\
Normal size for gestational age & $6459(82.48)$ \\
\hline
\end{tabular}

\begin{tabular}{|c|c|}
\hline IMH $(n=342)$ & Crude OR $(95 \% \mathrm{Cl})$ \\
\hline $11(3.22)$ & $1.25(0.68-2.32)$ \\
\hline $31(9.06)$ & $1.62(1.11-2.37)$ \\
\hline $300(87.72)$ & 1.00 (ref) \\
\hline $13(3.80)$ & $0.92(0.52-1.62)$ \\
\hline $63(18.42)$ & $1.49(1.12-1.97)$ \\
\hline 266 (77.78) & 1.00 (ref) \\
\hline
\end{tabular}

\begin{tabular}{l}
$\begin{array}{c}\text { Adjusted OR } \\
(95 \% \mathrm{Cl})^{\text {model1 }}\end{array}$ \\
\hline $1.08(0.50-2.35)$ \\
$\mathbf{1 . 8 3 ( 1 . 1 7 - 2 . 8 6 )}$ \\
$1.00($ ref $)$ \\
$0.78(0.38-6.61)$ \\
$1.28(0.90-1.83)$ \\
$1.00($ ref $)$
\end{tabular}

\begin{tabular}{l}
\multicolumn{1}{c}{$\begin{array}{c}\text { Adjusted OR } \\
(95 \% \mathrm{Cl})^{\text {model2 }}\end{array}$} \\
\hline $1.11(0.51-2.42)$ \\
$\mathbf{1 . 6 4}(\mathbf{1 . 0 1 - 2 . 6 7 )}$ \\
1.00 (ref) \\
$0.81(0.39-1.66)$ \\
$1.09(0.74-1.61)$ \\
1.00 (ref) \\
\hline
\end{tabular}

Model 1. Adjusted for BMI, health insurance, gravidity, parity, family history of chronic disease and newborn sex; Model 2. Model $1+$ maternal diabetes status.

aLow birth weight; 'bsmall for gestational age of infant; clarge for gestational age of infant. Bold indicates statistical significance, $P<0.05$.

\section{Results}

The study population consisted of 8173 women, of whom $342(4.18 \%)$ were diagnosed with IMH. Women with an IMH diagnosis were more likely to be underweight, primipara and without previous gravidity compared with euthyroid women. There was no significant difference in maternal age, menarche age, newborn sex or family history of chronic diseases between the euthyroid and IMH groups $(P>0.05)$ (Table 1$)$.

The neonatal weights from euthyroid mothers and IMH mothers were $3348.56 \pm 437.50 \mathrm{~g}$ and $3387.00 \pm 494.00 \mathrm{~g}$ $(t=677.24, P<.0001)$, respectively. Table 2 shows the univariate and multiple logistic regression analyses to assess the association between IMH and neonatal outcomes. We observed that IMH was associated with an increased risk of macrosomia after adjusting for maternal BMI, health insurance, newborn sex, family history of chronic diseases, parity and gravidity (adjusted $\mathrm{OR}=1.83$, 95\% CI: 1.17-2.86), but not with LBW (adjusted OR $=1.08$, 95\% CI: 0.50-2.35). After additionally adjusting for maternal diabetes status, the association between IMH and macrosomia was still statistically significant (adjusted $\mathrm{OR}=1.64,95 \% \mathrm{CI}: 1.04-2.67)$. When the newborns were categorised into three groups according to birth weight reference percentiles for Chinese babies, we observed that there was no association between IMH and risk of small gestational age of the infant (SGA) $(\mathrm{OR}=0.81$,
95\% CI: 0.39-1.66) or large gestational age of the infant (LGA) (OR=1.09, 95\% CI: 0.74-1.61).

In terms of pregnancy complications, we observed that IMH was associated with an increased risk of hypertensive disorders of pregnancy (OR=2.21, 95\% CI: $1.28-3.82)$ but not for GDM (OR=1.40, 95\% CI: 0.98-2.00), preeclampsia $(\mathrm{OR}=1.22$, 95\% CI: 0.37-4.04), placenta abruption $(\mathrm{OR}=1.46,95 \% \mathrm{CI}: 0.44-4.89)$, placenta previa $(\mathrm{OR}=2.24$, 95\% CI: $0.51-9.86)$ or preterm delivery $(\mathrm{OR}=0.83$, 95\% CI: 0.42-1.65) (Table 3).

When stratified by trimester, we observed a statistically significant association between IMH and increased risk of hypertensive disorders of pregnancy in the second trimester $(\mathrm{OR}=2.66,95 \% \mathrm{CI}: 1.38-5.10)$ but not in the first trimester ( $\mathrm{OR}=1.47,95 \% \mathrm{CI}$ : 0.51-4.19) (Table 4). Different from the main analysis, we observed that IMH was not associated with macrosomia in either the first or second trimester but was significantly associated with an increased risk for placenta abruption in the second trimester $(\mathrm{OR}=3.64,95 \% \mathrm{CI}: 1.07-12.41)$ (Table 5).

\section{Discussion}

In this study, the prevalence of IMH was $4.18 \%$, which is consistent with data from mildly iodine-deficient areas (16). Our study indicated that IMH diagnosed during the second trimester was associated with an increased

Table 3 Association of IMH and pregnancy complications.

\begin{tabular}{lcc}
\hline Pregnancy complications & & Euthyroid $(n=7831)$ \\
${$\cline { 1 - 1 }$M^{a}} }$ & & $1,002(13.30)$ \\
Placenta previa & & $30(0.38)$ \\
Placenta abruption & $60(0.77)$ \\
Hypertensive disorders of pregnancy & $222(2.83)$ \\
Preeclampsia & $71(0.91)$ \\
Preterm delivery & $327(4.18)$ \\
\hline
\end{tabular}

\begin{tabular}{c}
\hline IMH $(n=342)$ \\
\hline $59(18.21)$ \\
$4(1.17)$ \\
$3(0.88)$ \\
$20(5.85)$ \\
$4(1.17)$ \\
$16(4.68)$ \\
\hline
\end{tabular}

\begin{tabular}{l}
\hline Crude OR $(95 \% \mathrm{Cl})$ \\
\hline $1.45(1.09-1.94)$ \\
$1.15(0.36-3.67)$ \\
$3.08(1.08-8.97)$ \\
$\mathbf{2 . 1 3}(1.33-3.40)$ \\
$1.29(0.47-3.56)$ \\
$1.13(0.67-1.88)$ \\
\hline
\end{tabular}

\begin{tabular}{c} 
Adjusted OR $(95 \% \mathrm{Cl})^{*}$ \\
\hline $1.40(0.98-2.00)$ \\
$1.46(0.44-4.89)$ \\
$2.24(0.51-9.86)$ \\
$\mathbf{2 . 2 1}(1.28-3.82)$ \\
$1.22(0.37-4.04)$ \\
$0.83(0.42-1.65)$
\end{tabular}

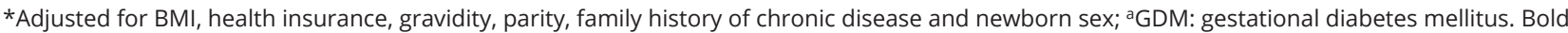
indicates statistical significance, $P<0.05$. 
Table 4 Trimester-specific prevalence of perinatal outcomes according to the thyroid function.

\begin{tabular}{|c|c|c|c|c|}
\hline \multirow[b]{2}{*}{ Pregnancy outcomes } & \multicolumn{2}{|c|}{ First trimester $(<13$ weeks, $\boldsymbol{n}=2208)$} & \multicolumn{2}{|c|}{ Second trimester (13-20 weeks, $n=5965)$} \\
\hline & Euthyroid $(n=2107)$ & $\mathrm{IMH}(n=101)$ & Euthyroid $(n=5724)$ & $\mathrm{IMH}(n=241)$ \\
\hline LBW $^{a}$ & $63(2.99)$ & $3(2.97)$ & $147(2.57)$ & $8(3.32)$ \\
\hline Macrosomia & $109(5.17)$ & $11(10.89)$ & $348(6.08)$ & $20(8.30)$ \\
\hline$S G A^{b}$ & $91(4.32)$ & $2(1.98)$ & $253(4.42)$ & $11(4.56)$ \\
\hline LGA $^{c}$ & $264(12.53)$ & $19(18.81)$ & $764(13.35)$ & $44(18.26)$ \\
\hline Preterm delivery & $93(4.41)$ & $2(1.98)$ & $234(4.09)$ & $14(5.81)$ \\
\hline $\begin{array}{l}\text { Hypertensive disorders of } \\
\text { pregnancy }\end{array}$ & $57(2.71)$ & $4(3.96)$ & $165(2.88)$ & $16(6.64)$ \\
\hline Preeclampsia & $15(0.71)$ & $2(1.98)$ & $56(0.98)$ & $2(0.83)$ \\
\hline $\mathrm{GDM}^{\mathrm{d}}$ & $260(12.97)$ & $18(18.95)$ & $742(13.42)$ & $41(17.90)$ \\
\hline placenta previa & $19(0.90)$ & $1(0.99)$ & $41(0.72)$ & $2(0.83)$ \\
\hline Placenta abruption & $10(0.47)$ & $1(0.99)$ & $20(0.35)$ & $3(1.24)$ \\
\hline
\end{tabular}

${ }^{a}$ Low birth weight; ${ }^{b}$ small for gestational age of infant; clarge for gestational age of infant; ${ }^{d}$ gestational diabetes mellitus.

risk of hypertensive disorders of pregnancy and placenta abruption but not with LBW or macrosomia, GDM, preterm delivery, large or small gestational age for infant or placenta previa.

Thyroid dysfunction during pregnancy is a matter of concern today, due to its widespread presence in pregnant women and the potential risk to children's neurodevelopment. However, its relationship with clinical obstetric trimester variation is still controversial $(17,18,19)$. The aetiology of IMH is still not well known, but iodine deficiency is proposed as a main one (20). Although iodised salt policy has been performed nationwide since 1995 in China, many studies have indicated that iodine deficiency is still universal among pregnant women in early pregnancy in Shanghai $(21,22,23)$.

Our study is also in accordance with a previous study, which indicated that IMH identified in the second trimester of gestation was a risk factor for gestational hypertension, with an odds ratio equal to $4.02(P<0.01)(19)$. However, Zhang Yong et al. reported that the incidence of hypertensive disorders of pregnancy was not significantly correlated with maternal fT4 levels, whereas IMH in the third trimester of pregnancy carried an increased risk of developing preeclampsia (24). In our study, we observed that IMH was associated with hypertensive disorders of pregnancy but not with preeclampsia. In clinics, hypertensive disorders of pregnancy were diagnosed after 20 gestational weeks. It is difficult to state the time sequence of IMH in the third trimester and the risk of preeclampsia, which could be a reverse causation. It was reported that there is a dose-response relationship between fT4 level and risk of hypertension (25), and adenosine and its analogues or related kinases could be important bridges between hypothyroxinaemia and hypertensive disorders of pregnancy (24). However, the mechanism still needs to be investigated further.

We observed that IMH is related to an increased risk of macrosomia, which was also reported by Goldman et al. (17). When considering gestational age, we did not observe an association of IMH with LGA or SGA infants,

Table 5 Trimester-specific association of IMH and perinatal outcomes.

\begin{tabular}{|c|c|c|c|c|}
\hline \multirow[b]{2}{*}{ Pregnancy outcomes } & \multicolumn{2}{|c|}{ First trimester ( $<13$ weeks) } & \multicolumn{2}{|c|}{ Second trimester (13-20 weeks) } \\
\hline & Crude OR $(95 \% \mathrm{Cl})$ & Adjusted OR $(95 \% \mathrm{Cl})$ * & Crude OR $(95 \% \mathrm{Cl})$ & Adjusted OR $(95 \% \mathrm{Cl})^{*}$ \\
\hline LBW $^{\mathrm{a}}$ & $1.06(0.33-3.44)$ & $1.08(0.33-3.53)$ & $1.34(0.65-2.76)$ & $1.08(0.39-3.02)$ \\
\hline Macrosomia & $2.25(1.17-4.33)$ & $1.91(0.94-3.88)$ & $1.41(0.88-2.26)$ & $1.71(0.95-3.07)$ \\
\hline$S_{G} A^{b}$ & $0.48(0.12-1.99)$ & $0.53(0.13-2.21)$ & $1.10(0.59-2.05)$ & $0.91(0.39-2.12)$ \\
\hline $\operatorname{LGA}^{\mathrm{c}}$ & $1.58(0.94-2.64)$ & $1.47(0.85-2.53)$ & $1.46(1.04-2.04)$ & $1.16(0.72-1.86)$ \\
\hline Preterm delivery & $0.44(0.11-1.80)$ & $0.48(0.12-1.98)$ & $1.45(0.83-2.52)$ & $1.09(0.50-2.40)$ \\
\hline $\begin{array}{l}\text { Hypertensive disorders of } \\
\text { pregnancy }\end{array}$ & $1.48(0.53-4.17)$ & $1.47(0.51-4.19)$ & $2.40(1.41-4.07)$ & $2.66(1.38-5.10)$ \\
\hline Preeclampsia & $2.82(0.64-12.49)$ & $2.85(0.63-12.96)$ & $0.85(0.21-3.49)$ & $0.56(0.07-4.20)$ \\
\hline $\mathrm{GDM}^{\mathrm{d}}$ & $1.57(0.92-2.66)$ & $1.49(0.85-2.62)$ & $1.41(1.00-1.99)$ & $1.36(0.86-2.15)$ \\
\hline placenta previa & $1.10(0.15-8.29)$ & $0.84(0.11-6.56)$ & $1.16(0.28-4.82)$ & $1.62(0.39-7.37)$ \\
\hline Placenta abruption & $2.10(0.27-16.54)$ & $2.22(0.28-7.77)$ & $3.60(1.06-2.18)$ & $3.64(1.07-12.41)$ \\
\hline
\end{tabular}

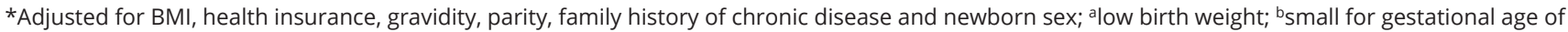
infant; 'large for gestational age of infant; ${ }^{d}$ gestational diabetes mellitus. Bold indicates statistical significance, $P<0.05$.

https://ec.bioscientifica.com https://doi.org/10.1530/EC-19-0088 (c) 2019 The authors Published by Bioscientifica Ltd

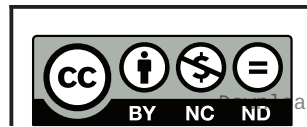

This work is licensed under a Creative Commons Attribution-NonCommercial-NoDerivatives 4.0 Internationab License.ifica com at $04 / 26 / 2023$ 10:43:07AM 
which is in contrast to previous studies $(19,26)$. Although gestational age was significantly different in the two groups (275.4 days vs 274.5 days), a 1-day difference is not clinically important and could not bias the association of IMH on birth weight. Because hyperglycaemia is a risk factor for macrosomia (27), we also performed sensitivity analysis by adjusting gestational age and GDM, which showed no obvious change in estimates. Of interest is a study that reported increased odds of LGA in non-Hispanic white women with hypothyroidism but increased odds of SGA in Hispanic black women with hypothyroidism (28). Hence, we speculated that the association between IMH and macrosomia might be biased by unmeasured confounders, such as nutrition supplement, ethnicity and so on. We also observed an increased risk of placenta abruption in women with hypothyroxinaemia, but this observation was imprecise due to sparse data (two cases in the IMH group).

A meta-analysis that included 15 studies showed that IMH had no association with preterm delivery, which agrees with our study (29). No association was observed between IMH and GDM, which was also supported by previous study (16). Although studies reported that thyroid dysfunction was more prevalent in women with GDM (30), and free T4 is a potential risk factor for GDM (12), most studies reported an association between clinical or subclinical thyroid dysfunction and risk of GDM (31, 32, 33) but not of IMH.

There are several strengths in our study. First, we used specific trimester reference ranges for TSH and fT4 in our institution instead of the universal World Health Organization (WHO) recommended range. Second, none of the women with isolated hypothyroxinaemia was prescribed levothyroxine in our institution, so bias regarding the treatment for hypothyroxinaemia could be excluded. Third, the large sample size was another advantage of this study, which partly guaranteed the robustness of the results. The main limitation was that we did not measure the iodine level, which is a key aetiology of IMH. Urinary iodine deficiency is universal in Shanghai, China $(21,22)$. However, the complete association between IMH and iodine deficiency is still controversial. Some other factors have also been proposed as potential aetiologies of hypothyroxinaemia, such as environmental disruptors, obesity and imbalance between pro- and antiangiogenic factors $(21,34)$.

The prevalence of IMH is high in early pregnancy in Shanghai, and IMH identified during the second trimester is associated with an increased risk of hypertensive disorders of pregnancy and placenta abruption.

\section{Declaration of interest}

The authors declare that there is no conflict of interest that could be perceived as prejudicing the impartiality of the research reported.

\section{Funding}

This study was supported by the National Natural Science Foundation of China (81602860, 81703233, 81673179, 81402687), Key Laboratory of Public Health Safety (Fudan University), Ministry of Education, China (GW2019-10), the Shanghai Hospital Development Centre (16CR1014A), the Shanghai Municipal Commission of Health and Family Planning (20174Y0010, 20184Y0078, 201540165) the and Shanghai Municipal Medical and Health Discipline Construction projects (2017ZZ02015).

\section{Author contribution statement}

SXJ drafted the article. All authors revised it critically for important intellectual content. SXJ and ZHY gave substantial contributions to conception and design, data management and analysis. All authors approved the final version to be published.

\section{Acknowledgements}

Tony Duan and Jing Hua: contributed equally to this work.

\section{References}

1 Haddow JE, Palomaki GE, Allan WC, Williams JR, Knight GJ, Gagnon J, O'Heir CE, Mitchell ML, Hermos RJ, Waisbren SE, et al. Maternal thyroid deficiency during pregnancy and subsequent neuropsychological development of the child. New England Journal of Medicine 1999341 549-555. (https://doi.org/10.1056/ NEJM199908193410801)

2 Liu X, Andersen SL, Olsen J, Agerbo E, Schlunssen V, Dharmage SC \& Munk-Olsen T. Maternal hypothyroidism in the perinatal period and childhood asthma in the offspring. Allergy 201873 932-939. (https://doi.org/10.1111/all.13365)

3 Derakhshan A, Korevaar TIM, Taylor PN, Levie D, Guxens M, Jaddoe VWV, Nelson SM, Tiemeier H \& Peeters RP. The Association of Maternal Thyroid Autoimmunity during pregnancy with child IQ. Journal of Clinical Endocrinology and Metabolism 2018103 3729-3736. (https://doi.org/10.1210/jc.2018-00743)

4 Thorpe-Beeston JG, Nicolaides KH, Felton CV, Butler J \& McGregor AM. Maturation of the secretion of thyroid hormone and thyroid-stimulating hormone in the fetus. New England Journal of Medicine 1991324 532-536. (https://doi.org/10.1056/ NEJM199102213240805)

5 Obregon MJ, Calvo RM, Del Rey FE \& de Escobar GM. Ontogenesis of thyroid function and interactions with maternal function. Endocrine Development 200710 86-98. (https://doi.org/10.1159/000106821)

6 Andersen SL, Olsen J \& Laurberg P. Maternal thyroid disease in the Danish National Birth Cohort: prevalence and risk factors. European Journal of Endocrinology $2016 \mathbf{1 7 4}$ 203-212. (https://doi.org/10.1530/ EJE-15-0816)

7 Shan ZY, Chen YY, Teng WP, Yu XH, Li CY, Zhou WW, Gao B, Zhou JR, Ding B, Ma Y, et al. A study for maternal thyroid hormone deficiency during the first half of pregnancy in China. European Journal of Clinical Investigation 200939 37-42. (https://doi. org/10.1111/j.1365-2362.2008.02055.x)

8 Dong AC \& Stagnaro-Green A. Differences in diagnostic criteria mask the true prevalence of thyroid disease in pregnancy: a systematic review and meta-analysis. Thyroid 201929 278-289. (https://doi. org/10.1089/thy.2018.0475) 
9 Alexander EK, Pearce EN, Brent GA, Brown RS, Chen H, Dosiou C, Grobman WA, Laurberg P, Lazarus JH, Mandel SJ, et al. 2017 Guidelines of the American Thyroid Association for the diagnosis and management of thyroid disease During pregnancy and the postpartum. Thyroid 201727 315-389. (https://doi.org/10.1089/ thy.2016.0457)

10 Stagnaro-Green A, Abalovich M, Alexander E, Azizi F, Mestman J, Negro R, Nixon A, Pearce EN, Soldin OP, Sullivan S, et al. Guidelines of the American Thyroid Association for the diagnosis and management of thyroid disease during pregnancy and postpartum. Thyroid 201121 1081-1125. (https://doi.org/10.1089/thy.2011.0087)

11 Abdel Rahman AH, Aly Abbassy H \& Abbassy AA. Improved in vitro fertilization outcomes after treatment of subclinical hypothyroidism in infertile women. Endocrine Practice 201016 792-797. (https://doi. org/10.4158/EP09365.OR)

12 Yang S, Shi FT, Leung PCK, Huang HF \& Fan JX. Low thyroid hormone in early pregnancy is associated With an increased risk of gestational diabetes mellitus. Journal of Clinical Endocrinology and Metabolism 2016101 4237-4243. (https://doi.org/10.1210/jc.20161506)

13 Moleti M, Trimarchi F \& Vermiglio F. Doubts and concerns about isolated maternal hypothyroxinemia. Journal of Thyroid Research 2011 2011 463029. (https://doi.org/10.4061/2011/463029)

14 Ying H, Tang YP, Bao YR, Su XJ, Cai X, Li YH \& Wang DF. Maternal TSH level and TPOAb status in early pregnancy and their relationship to the risk of gestational diabetes mellitus. Endocrine $2016 \mathbf{5 4}$ 742-750. (https://doi.org/10.1007/s12020-016-1022-6)

15 Dai L, Deng C, Li Y, Zhu J, Mu Y, Deng Y, Mao M, Wang Y, Li Q, Ma S, et al. Birth weight reference percentiles for Chinese. PLOS ONE 20149 e104779. (https://doi.org/10.1371/journal.pone.0104779)

16 Casey BM, Dashe JS, Spong CY, McIntire DD, Leveno KJ \& Cunningham GF. Perinatal significance of isolated maternal hypothyroxinemia identified in the first half of pregnancy. Obstetrics and Gynecology 2007109 1129-1135. (https://doi.org/10.1097/01. AOG.0000262054.03531.24)

17 Cleary-Goldman J, Malone FD, Lambert-Messerlian G, Sullivan L, Canick J, Porter TF, Luthy D, Gross S, Bianchi DW \& D'Alton ME. Maternal thyroid hypofunction and pregnancy outcome. Obstetrics and Gynecology 2008112 85-92. (https://doi.org/10.1097/ AOG.0b013e3181788dd7)

18 Furnica RM, Gruson D, Lazarus JH, Maiter D, Bernard P \& Daumerie C. First trimester isolated maternal hypothyroxinaemia: adverse maternal metabolic profile and impact on the obstetrical outcome. Clinical Endocrinology 201786 576-583. (https://doi. org/10.1111/cen.13301)

19 Gong X, Liu A, Li Y, Sun H, Li Y, Li C, Yu X, Fan C, Shan Z \& Teng W. The impact of isolated maternal hypothyroxinemia during the first and second trimester of gestation on pregnancy outcomes: an intervention and prospective cohort study in China. Journal of Endocrinological Investigation 2018. (https://doi.org/10.1007/s40618018-0960-7)

20 Kibirige MS, Hutchison S, Owen CJ \& Delves HT. Prevalence of maternal dietary iodine insufficiency in the north east of England: implications for the fetus. Archives of Disease in Childhood: Fetal and Neonatal Edition 200489 F436-F439. (https://doi.org/10.1136/ adc.2003.029306)

21 Wei Z, Wang W, Zhang J, Zhang X, Jin L \& Yu X. Urinary iodine level and its determinants in pregnant women of Shanghai, China. British Journal of Nutrition 2015113 1427-1432. (https://doi.org/10.1017/ S0007114515000665)
22 Wang Z, Liu P, Su X, Zou S, Song J \& Liu S. A comparative study of iodized salt programs: Shanghai and Switzerland. Biological Trace Element Research 2019187 59-64. (https://doi.org/10.1007/s12011018-1370-6)

23 Wang Z, Liu P, Su X, Zou S, Song J \& Liu S. A comparison of iodine status in children and pregnant women after a policy change in the iodized salt standard in Shanghai, China. Biological Trace Element Research 2018185 275-281. (https://doi.org/10.1007/s12011-0181257-6)

24 Zhang Y, Dai XB, Yang S, Zhang C, Han M, Huang HF \& Fan JX. Maternal low thyroxin levels are associated with adverse pregnancy outcomes in a Chinese population. PLoS ONE $201712 \mathrm{e} 0178100$. (https://doi.org/10.1371/journal.pone.0178100)

25 Zhou J, Du J, Ma B, Liu X, Qiu H, Li J \& Wang X. Thyroid hormone changes in women with pre-eclampsia and its relationship with the presence of pre-eclampsia. Zhonghua Fu Chan Ke Za Zhi 201449 109-113. (https://doi.org/10.3760/cma.j.issn.0529567x.2014.02.007)

26 Su PY, Huang K, Hao JH, Xu YQ, Yan SQ, Li T, Xu YH \& Tao FB. Maternal thyroid function in the first twenty weeks of pregnancy and subsequent fetal and infant development: a prospective population-based cohort study in China. Journal of Clinical Endocrinology and Metabolism 201196 3234-3241. (https://doi. org/10.1210/jc.2011-0274)

27 Hosseini E \& Janghorbani M. Systematic review and meta-analysis of diagnosing gestational diabetes mellitus with one-step or two-step approaches and associations with adverse pregnancy outcomes. International Journal of Gynaecology and Obstetrics 2018143 137-144. (https://doi.org/10.1002/ijgo.12644)

28 Mannisto T, Mendola P, Reddy U \& Laughon SK. Neonatal outcomes and birth weight in pregnancies complicated by maternal thyroid disease. American Journal of Epidemiology 2013178 731-740. (https:// doi.org/10.1093/aje/kwt031)

29 Sheehan PM, Nankervis A, Araujo Junior E \& Da Silva Costa F. Maternal thyroid disease and preterm birth: systematic review and meta-analysis. Journal of Clinical Endocrinology and Metabolism 2015 100 4325-4331. (https://doi.org/10.1210/jc.2015-3074)

30 Oguz A, Tuzun D, Sahin M, Usluogullari AC, Usluogullari B, Celik A $\&$ Gul K. Frequency of isolated maternal hypothyroxinemia in women with gestational diabetes mellitus in a moderately iodinedeficient area. Gynecological Endocrinology 201531 792-795. (https:// doi.org/10.3109/09513590.2015.1054801)

31 Tudela CM, Casey BM, McIntire DD \& Cunningham FG. Relationship of subclinical thyroid disease to the incidence of gestational diabetes. Obstetrics and Gynecology 2012119 983-988. (https://doi. org/10.1097/AOG.0b013e318250aeeb)

32 Karakosta P, Alegakis D, Georgiou V, Roumeliotaki T, Fthenou E, Vassilaki M, Boumpas D, Castanas E, Kogevinas M \& Chatzi L. Thyroid dysfunction and autoantibodies in early pregnancy are associated with increased risk of gestational diabetes and adverse birth outcomes. Journal of Clinical Endocrinology and Metabolism 2012 97 4464-4472. (https://doi.org/10.1210/jc.2012-2540)

33 Stohl HE, Ouzounian J, Rick AM, Hueppchen NA \& Bienstock JL. Thyroid disease and gestational diabetes mellitus (GDM): is there a connection? Journal of Maternal-Fetal and Neonatal Medicine 201326 1139-1142. (https://doi.org/10.3109/14767058.2013.773309)

34 Dosiou C \& Medici M. MANAGEMENT of ENDOCRINE DISEASE: Isolated maternal hypothyroxinemia during pregnancy: knowns and unknowns. European Journal of Endocrinology 2017176 R21-R38. (https://doi.org/10.1530/EJE-16-0354)

Received in final form 21 February 2019

Accepted 19 March 2019

Accepted Preprint published online 19 March 2019 https://ec.bioscientifica.com https://doi.org/10.1530/EC-19-0088 (c) 2019 The authors Published by Bioscientifica Ltd
This work is licensed under a Creative Commons Attribution-NonCommercial-NoDerivatives 4.0 Internationab sicense.ifica . com at 04/26/2023 10:43:07AM 